\title{
ANÁLISE DO LUCRO NA ATIVIDADE EMPRESARIAL: DO PERVERSO AO NECESSÁRIO
}

\author{
Sandro Mansur Gibran* \\ Luiza Helena Gonçalves ${ }^{\dagger}$
}

\section{Resumo:}

Com a Constituição Federal de 1988 a atividade empresarial revelou-se como principal personagem na ordem econômica e na efetivação de inúmeros valores sociais. Tal contexto, porém, acabou por evidenciar uma concepção negativa do lucro, já que os interesses privados do empresário seriam incompatíveis com o fim constitucional da empresa. Contrário a essa visão, o presente trabalho buscou ressaltar que o lucro deve ser considerado como um agente catalisador. Valendo-se do método dedutivo a pesquisa em apreço pretendeu demonstrar que é por meio da lucratividade que a empresa realiza os princípios constitucionais, concluindo-se que valores sociais e lucro devem coexistir.

Palavras-chave: Lucro; Ordem Econômica; Empresa; Fim Social; Coexistência.

\section{ANALYSIS OF PROFIT IN BUSINESS ACTIVITY: FROM THE PERVERSE TO THE NECESSARY}

\begin{abstract}
:
With the Federal Constitution of 1988 the business activity was revealed as main personage in the economic order and in the accomplishment of numerous social values. This context, however, evidenced a negative conception of profit, since the private interests of the entrepreneur would be incompatible with the constitutional purpose of the company. Against this view, the present work sought to emphasize that profit should be considered as a catalyst. Using the deductive method, the present research aimed to demonstrate that it is through profitability that the company realizes the constitutional principles, concluding that social values and profit must coexist.
\end{abstract}

Keywords: Profit; Economic Order; Company; Social Purpose; Coexistence.

\footnotetext{
* Doutor em Direito Econômico e Socioambiental pela Pontifícia Universidade Católica do Paraná (2009). Mestre em Direito Social e Econômico pela Pontifícia Universidade Católica do Paraná (2003). Graduado em Direito pela Faculdade de Direito de Curitiba (1996). É advogado. Professor de Direito Empresarial junto ao Centro de Estudos Jurídicos do Paraná - CEJPR e na Escola da Magistratura Federal do Paraná - ESMAFE/PR. Professor visitante na Universidade da Indústria da Federação das Indústrias do Estado do Paraná - UNINDUS. Coordenador do Curso de Pós-Graduação em Direito Empresarial do UNICURITIBA. Professor permanente no Programa de Mestrado em Direito Empresarial e Cidadania do UNICURITIBA. Realiza estágio Pós-Doutoral na Universidade Federal do Paraná (2017/2017). Tem experiência em: Direito Empresarial Societário. Função Social da Atividade Empresarial. Negócios Empresariais. Consumo Consciente e Sustentável.

${ }^{+}$Mestranda em Direito Empresarial e Cidadania pelo Centro Universitário Curitiba - UniCuritiba. Graduada em Direito pela Faculdade de Direito de Curitiba - FDC (2004). Possui especialização em Direito Processual Civil pelo Instituto de Direito Romeu Felipe Bacellar (2006) e MBA (nível de especialização Lato Sensu) em Advocacia Empresarial (2016). Associada ao Conselho Nacional de Pesquisa e Pós-Graduação em Direito (CONPEDI). Suas pesquisas estão concentradas na área do Direito com ênfase em Direito Empresarial.
} 


\section{INTRODUÇÃO}

A partir do momento que a empresa passou a ser uma atividade e, com isso, um instrumento para a efetivação de inúmeros serviços essenciais à sociedade, o seu estudo ganhou significativa relevância.

$\mathrm{Na}$ mesma toada, a intrínseca relação entre o capital econômico e a sociedade fez com que a empresa conquistasse papel essencial no que tange à produção de riquezas (de maneira geral) e, consequentemente, inarredável interesse público.

Tal cenário se consolida com o advento da Constituição Federal de 1988, pois sob a égide dos princípios entabulados na ordem econômica e financeira, a atividade empresarial assumiu uma finalidade muito mais ampla do que a circulação de bens e serviços. Foi a empresa alcançada pelos ditames da existência digna e justiça social.

Neste compasso, insta destacar como inerente à atividade empresarial o seu direcionamento para a consecução dos interesses do empresário, os quais estão intrinsecamente ligados a um proveito financeiro.

Todavia, com a empresa assumindo papel de principal personagem da ordem econômica e, por via de consequência, vetor de valores constitucionais, tais interesses pessoais de lucro, por carregarem em seu bojo uma visão bastante negativa, passaram a ser avaliados em contraposição direta à noção de interesses coletivos e sociais.

Daí advém o grande desafio no âmbito da atividade empresarial, ou seja, a coexistência entre uma atuação social, e, ao mesmo tempo, uma preocupação genuína com os interesses privados daqueles que nela atuam e investem.

Dito isto, o presente artigo busca realizar uma análise acerca do lucro de maneira a afastá-lo de qualquer aspecto imoral, bem como distanciá-lo de uma eventual incompatibilidade com a finalidade social da empresa.

Não obstante o necessário introito teórico acerca do conceito de empresa e suas características, bem como uma breve análise acerca do lucro enquanto uma das finalidades da atividade empresarial e, igualmente, como um eventual objetivo espúrio, o fito maior do presente trabalho é o de alavancar o lucro ao patamar de verdadeiro fomento da empresa.

Com o devido suporte doutrinário, e baseado em uma metodologia dedutiva, pretende-se, ao final, convalidar o entendimento acerca da plena e necessária coexistência entre o objetivo de lucro e a vertente social da empresa. 
Isso porque, somente uma empresa lucrativa poderá atingir com plenitude a efetivação dos ditames constitucionais que foram atribuídos à ordem econômica nacional.

\section{BREVES CONSIDERAÇÕES SOBRE O CONCEITO DE EMPRESA E O LUCRO}

Desde os chamados atos de comércio até o advento da teoria da empresa, tem-se uma transição marcada pelo esvaziamento das ações dos chamados comerciantes (aqueles que intermediavam bens levando-os dos produtores até os que deles necessitavam), em favor da consolidação de uma atividade economicamente organizada e direcionada ao mercado, surgindo, com isso, a figura do empresário.

Logo é possível afirmar que (BULGARELLI, 1998, p. 67):

[...] o conceito tradicional de comerciante é substituído pelo de empresário (como ocorreu no Código Civil italiano em 1942), enquanto não mais se parte do ato de comércio isolado, mas da sequência de atos, portanto a atividade desempenhada pelo empresário.

Daí porque, em que pese não existir um conceito de empresa no arcabouço legal brasileiro, socorre-se a doutrina do conteúdo de empresário entabulado no artigo 966 do Código Civil, para o fim de definir a empresa como uma "atividade econômica organizada", voltada principalmente para a "produção ou circulação de bens e serviços" (COELHO, 2005, p. 12). Ou, ainda, como um conjunto de "organismos econômicos, que se concretizam na organização dos fatores de produção e se propõem a satisfação das necessidades alheias, e, mais precisamente, das exigências do mercado geral" (REQUIÃO, 2010, p. 73).

Conforme preceitua Gladston Mamede (2009, p. 5):

O desafio teórico passou a ser a definição do que seja a empresa. O legislador brasileiro não se ocupou minuciosamente disso, resumindo-se a afirmar que empresários e sociedades empresarias são aqueles que exercem profissionalmente atividade econômica organizada para a produção ou a circulação de bens ou de serviços.

De todo modo cabe ressaltar que a empresa (FERNANDEZ, 2010, p. 260): 
[...] deve ser uma atividade econômica, organizada, exercida profissionalmente para a produção ou a circulação de bens e serviços. Esses requisitos de empresarialidade foram herdados da Teoria da Empresa, contribuição italiana que representou um avanço no sentido de adaptar o ordenamento jurídico às mudanças ocorridas na estrutura econômica pós revolução industrial.

A partir disso, cumpre observar que na grande maioria das definições de empresa são constantes as noções de atividade, de organização, de profissionalidade, de fatores de produção (capital, trabalho, matéria-prima, etc.), os quais se direcionam à realização de uma prática de natureza eminentemente econômica no intuito de promover a circulação de bens e serviços.

E justamente por possuir este viés econômico é que também deve compor a percepção de empresa a ideia de lucro enquanto objetivo e resultado direto da "expressão dos bens de produção em dinamismo, em torno do qual se instala o relacionamento capital $\mathrm{x}$ trabalho e a partir da qual se desenrolam os processos econômicos privados" (GRAU, 2014, p. 173).

Com base nisso, a empresa deve ser vista como uma atividade "exercida com o objetivo de habitualidade e intenção de lucro" (MIRANDA, 2009, p.2), e como "uma organização de capital e de trabalho direcionada à produção ou à troca de bens e serviços com finalidade de lucro" (FAVATA, 2007, p. 256, tradução nossa). Ou, ademais, conforme preceitua Giuseppe Ferri "a empresa exige uma finalidade econômica qualificada, a de fazer um lucro" (2006, p. 42, tradução nossa).

Logo, uma vez que a "atividade econômica, na acepção da palavra, significa atividade produtiva", ao abrigo desta definição é possível afirmar que "tratando-se de empresas, o resultado da atividade econômica aparece na forma de lucro" (FERNANDEZ, 2010, p. 269-270).

O próprio Superior Tribunal de Justiça ao discorrer sobre a finalidade da empresa assim entendeu (BRASIL, 2004):

\footnotetext{
Nessa esteira, o novel Código Civil Brasileiro, em que pese não ter definido expressamente a figura da empresa, conceituou no art. 966 o empresário como "quem exerce profissionalmente atividade econômica organizada para a produção ou a circulação de bens ou de serviços " e, ao assim proceder, propiciou ao intérprete inferir o conceito jurídico de empresa como sendo o exercício organizado ou profissional de atividade econômica para a produção ou a circulação de bens ou de serviços.
} 
Por exercício profissional da atividade econômica, elemento que integra o núcleo do conceito de empresa, há que se entender a exploração de atividade com finalidade lucrativa.

De qualquer forma, seja por um aspecto jurídico, seja por uma vertente econômica, na busca por uma definição de empresa reputa-se importante destacar a visão entabulada por Cássio Machado Cavalli (2012, p. 238) no sentido de que:

[...] o diálogo entre o direito e a economia não se dá a partir de um emparelhamento entre um conceito econômico de empresa e um conceito jurídico, mas entre conceitos 
econômicos - como lucro, risco, etc., - e o papel que pode desempenhar na elaboração de uma fattispecie jurídica em congruência valorativa com uma finalidade normativa.

- Por fattispecie, expressão de origem italiana, deve-se entender como um fato particular sobre o qual se debruça determinado estudo ou análise com o intuito de se determinar um conceito ou definição (FAVATA, 2007, p. 216, tradução nossa). 
Por esta razão, torna-se relevante o tratamento da empresa com base em uma necessária interpretação valorativa de todos seus elementos caracterizadores, sobretudo no que tange às finalidades entabuladas na Constituição Federal de 1988 e à ordem econômica e financeira nacional.

Isso porque, com base no texto normativo constitucional, a empresa foi alçada a patamar de destaque e, nesta toada, assumiu a árdua tarefa de compatibilizar sua natureza lucrativa com as inúmeras atribuições sociais que lhe foram atribuídas.

Neste compasso pode-se afirmar que o lucro surge não apenas como uma pretensão de cunho individualista do empresário, mas como verdadeiro condicionante de fomento e de manutenção da própria atividade empresarial.

\section{O PAPEL DA EMPRESA NA EFETIVAÇÃO DA ORDEM ECONÔMICA CONSTITUCIONAL}

A Constituição Federal de 1988 consagrou em seu bojo princípios eminentemente capitalistas, estabelecendo como pilares valorativos da atividade empresarial a propriedade privada, a livre iniciativa e a liberdade de concorrência.

Ao mesmo tempo, o artigo 170 da Lei Maior, ao dispor acerca da ordem econômica nacional, trouxe em seu texto uma série de garantias diretamente ligadas ao princípio da dignidade, tais como justiça social, pleno emprego, redução de desigualdades, entre outros.

Assim, no que tange à ordem econômica, pode-se afirmar que, sob a ótica constitucional, a empresa assumiu uma dinâmica que vai muito além da simples circulação de bens ou serviços, bem como uma finalidade que em muito ultrapassa a mera consecução de lucro.

Face ao conteúdo valorativo entabulado pela Constituição Federal a empresa transformou-se em um baluarte de princípios, pois conforme escreve Carlos Aurélio Mota de Souza (2007, p. 49):

De fato, seu art. 170 vincula a ordem econômica a um fim social. A liberdade de iniciativa (empresarial) está dirigida a uma finalidade humana, a de garantir a existência digna das pessoas, conforme os ditames da justiça social, fundada em 
sólidos princípios: da soberania nacional (inciso I), da propriedade privada (inciso II), da função social da propriedade (inciso III), da livre concorrência (inciso IV), da defesa do consumidor (inciso V), da defesa do meio ambiente (inciso VI), da redução das desigualdades regionais (inciso VII), da busca do pleno emprego (inciso VIII), do favorecimento às empresas de pequeno porte (inciso IX).

É, portanto, dever constitucional do empresariado privilegiar esta justiça social, a fim de garantir a todos os cidadãos condições mínimas para satisfazer suas necessidades fundamentais, tanto físicas como espirituais, morais e artísticas.

Logo, tendo em vista o propósito de justiça social, a empresa assumiu posição de verdadeiro paradigma na existência e conformação da ordem econômica nacional, sendo possível afirmar que todo o processo econômico contemporâneo é alicerçado e impulsionado pela empresa.

Afinal é no âmbito da empresa que se une trabalho e livre iniciativa, da mesma forma que é pelo salário pago pelo empresário aos seus empregados que estes podem dispor de melhores condições de vida e usufruir de uma existência mais digna. Ainda, é pelos ativos gerados pela empresa (impostos recolhidos ao erário, bens produzidos, serviços disponibilizados, etc.) que as desigualdades sociais e regionais podem ser amenizadas.

Por isso que na ótica de Arnold Wald e Rodrigo Garcia da Fonseca (2005, p. 6), a empresa:

É, pois, o elemento central da economia moderna, caracterizada pelas suas várias facetas: entidade econômica, por ser centro de produção ou de circulação de bens, entidade social, por desenvolver uma verdadeira parceria entre capital e trabalho e, por fim, entidade jurídica, por constituir um complexo de direitos e de obrigações $[\ldots]$

Dito isto, a empresa deve ser reconhecida como instrumento de confirmação dos valores nacionais mais essenciais, pois é através da empresa que os fins contidos no artigo 170 da Constituição de 1988 podem ser observados. Em outras palavras, "a atividade empresária atende à sociedade possibilitando o exercício dos direitos básicos previstos na ordem econômica" (ZANZANELLI, 2014, p. 157).

Neste contexto, a atividade empresarial no Brasil ganhou contornos significativos e começou a desempenhar um papel extremamente desafiador: conciliar a livre iniciativa e a justiça social. 
Deixou a empresa de ser um simples instrumento de concretização dos objetivos de natureza privada e passou a ser ferramenta de efetivação dos interesses sociais, em nítida deferência aos princípios constitucionais conformadores da ordem econômica nacional.

Logo, cabe à empresa "conciliar, hoje, os interesses aparentemente conflitantes, mas materialmente convergentes, de investidores, administradores, empregados e consumidores, que constituem os grandes setores da vida nacional" (WALD; FONSECA, 2005, p. 9).

E esta realidade se deve ao fato de que (ARAUJO, 2005, p 112):

\begin{abstract}
Se em suas origens a empresa era pautada pela busca incessante e incondicional do lucro, apoiada na noção de que o proprietário poderia usar de seu bem como lhe aprouvesse, teve mais tarde, que se render às transformações que fizeram com que essa concepção individualista fosse gradativamente perdendo espaço, até que os direitos subjetivos abandonassem o cunho nitidamente egoísta que os caracterizava, recebendo limitações que lhes foram impostas em nome do interesse coletivo, da ordem pública e dos bons costumes, visando, com isso, não só regulamentar a atividade empresarial, mas principalmente, zelar para a construção de uma sociedade mais justa e igualitária.
\end{abstract}

Nesta tangente, Wilson José Gonçalves assevera que (2007, p. 16):

Com isto, pode-se afirmar que a empresa como um organismo, de suma importância e significado, seja como sociedade, seja como órgão do setor da economia produtiva, não tenha apenas a atribuição ou função coletora de rendimento e distribuição de lucro entre seus sócios.

Ou, ainda, como apregoa Fábio Konder Comparato (1995, p. 7), para quem "encarado o sistema econômico nacional em sua globalidade, aliás, seria absurdo considerar a atividade empresarial como matéria de exclusivo interesse privado".

Daí porque no âmbito da ordem econômica constitucional é garantida a livre iniciativa da empresa, ou seja, é assegurado o seu desenvolvimento como atividade organizada voltada à circulação de bens e serviços, mas desde que, para muito além dos interesses individuais do empresário, entre os quais está o lucro, a empresa deverá encerrar a realização de desígnios coletivos e sociais.

\title{
4 A VISÃO EGOÍSTA DO LUCRO E SUA EVENTUAL INCOMPATIBILIDADE COM O FIM CONSTITUCIONAL DA EMPRESA
}


Como visto, com o advento da Constituição Federal de 1988 a empresa ganhou amplitude expressiva, uma vez que, com espeque no artigo 170 de referido diploma, passou a servir de base não só para a atividade econômica puramente considerada (circulação de bens e serviços com intuito principal de lucratividade), mas também como viga mestra na efetivação de diversos princípios direcionados a fins sociais.

Se anteriormente a atividade empresarial tinha como um dos seus grandes objetivos o lucro, a partir do referido marco legislativo este propósito perdeu importância, passando, inclusive, a ser visto como algo vilipendioso e extremamente criticável.

Por óbvio que esta aversão ao lucro não é (e não era, ao tempo da vigência da Constituição Federal) algo novo. Aliás, atribui-se em grande monta à doutrina cristã a responsabilidade por associar o lucro à usura (expressão aqui utilizada no sentido de ganho especulativo e injusto) e, com isso, conferir-lhe uma índole condenável.

O fato é que a influência religiosa sobre a concepção do lucro foi tão significativa que as principais diferenças entre um lucro legítimo e aquele eventualmente abusivo (ou espúrio) se dissiparam.

E sobre o tema Leo Huberman ensina que (1981, p. 48):

\footnotetext{
Se alguém obtivesse numa transação mais do que o devido, estaria prejudicando a outrem, e isso estava errado. Santo Tomás de Aquino, o maior pensador religioso da Idade Média, condenou a "ambição do ganho". Embora se admitisse, com relutância, que o comércio era útil, os comerciantes não tinham o direito de obter numa transação mais do que o justo pelo seu trabalho.
}

Diante dos fins sociais atribuídos à ordem econômica nacional e, por via oblíqua, à própria empresa, o lucro se consolidou como uma grande mácula, distanciando-se dos fins da atividade empresarial, uma vez que a sua consumação se daria em nítido detrimento dos valores constitucionais.

Daí porque ainda persistem noções distorcidas sobre o tema, como aquelas nas quais “o dinheiro e lucro é o objetivo 'sagrado' que justifica os meios. Isto resulta numa especulação e exploração dos recursos naturais e humanos (trabalhadores) sem limites, causando enormes injustiças econômicas e sociais" (SIMULA, 2016).

Isso se deve ao fato de que "o empresário não pode, pois, ser um simples especulador, mas um criador de riqueza e de empregos, cabendo-lhe o papel de catalisador de 
um clima de prosperidade e segurança para o meio social no qual vive" (WALD; FONSECA, 2005, p. 37-38).

E neste sentido (ADMINISTRADORES, 2005):

\begin{abstract}
Entre economistas e acadêmicos, ninguém tem dúvida de que a maior missão de uma empresa é ser lucrativa. Sem lucro, não há geração de riqueza, crescimento, emprego, justiça social - não há, em suma, nada que justifique a existência das empresas. Mas o lucro está tão estigmatizado, tão satanizado na sociedade que os próprios empresários - embora, no íntimo, reconheçam sua importância - tomam cuidado, em público, para não defendê-lo com entusiasmo.
\end{abstract}

Ao evidenciarem os princípios previstos no artigo 170 da Constituição Federal os legisladores buscaram afastar qualquer possibilidade de não efetivação desses preceitos pelas empresas, as quais poderiam ser desvirtuadas justamente em função do lucro (Zanzanelli, 2014).

Este é o principal motivo pelo qual as atribuições sociais da empresa ganharam mais relevância do que a persecução do lucro.

Na ótica de Fábio Konder Comparato (1995, p. 11):

\begin{abstract}
O lucro não entra, na organização do sistema econômico, com as características de um oportore, de um dever supremo, ou então de uma liberdade fundamental do homem. É um simples licere, uma liceidade sem conteúdo impositivo, o que demonstra sua não inclusão na esfera do social, dos interesses comuns do povo, e sua pertinência ao campo dos interesses particulares, hierarquicamente inferiores àquele.
\end{abstract}

Tem-se, portanto, que a crítica ao lucro foi capaz de distorcer a importância e a própria essência da atividade empresarial, mormente diante da perspectiva constitucional dada à ordem econômica (e da qual a empresa privada é um dos principais personagens), haja vista a necessidade de se observar inúmeros princípios e valores com intuito de garantir a finalidade social da empresa.

Por esta razão é que, segundo assevera Wilson José Gonçalves (2007, p. 22), “a empresa moderna deve servir a comunidade e não dela servir-se, uma vez que esta assume ser instrumento de realização do bem-estar da comunidade e não um ente parasitário". 
Isso porque, "numa proporção de quase vinte para um, o público acredita que as grandes empresas 'deveriam eventualmente sacrificar uma parte de seus lucros para melhorar a vida de seus trabalhadores e suas comunidades"” (CHOMSKY, 1999, p. 31).

Deste cenário é que exsurge o grande desafio da atividade empresarial: compatibilizar a persecução de lucro e a realização dos valores constitucionais, ou seja, concretizar a intenção de cunho privativo (lucratividade), sem perder de vista os fins sociais a que se destina a empresa.

Nesta toada, uma escorreita compreensão do dilema é aquela na qual "o fim lucrativo pode ser um caráter normal da atividade econômica empreendedora, porém não pode ser considerado condição para a existência da empresa” (FERNANDEZ, 2010, p. 270).

Dito isto, a importância do debate sobre o tema recai, portanto, na busca por sedimentar a coexistência de ambas as finalidades da empresa, privativa e social, e, com isso, possibilitar que a ordem econômica idealizada pela Constituição Federal se concretize em sua plenitude.

\section{O LUCRO COMO FOMENTO DA ATIVIDADE EMPRESARIAL: UMA IMPERIOSA RESSIGNIFICAÇÃO}

Ao tratar sobre a importância da empresa Fábio Konder Comparato assevera que (1995, p. 3):

Se se quiser indicar instituição social que, pela sua influência, dinamismo e poder de transformação, sirva de elemento explicativo e definidor da civilização contemporânea, a escolha é indubitável: essa instituição é a empresa.

É dela que depende, diretamente, a subsistência da maior parte da população ativa neste país pela organização do trabalho assalariado.

[...]

É das empresas que provém a grande maioria dos bens e serviços consumidos pelo povo, e é deles que o Estado retira a parcela maior de suas receitas fiscais.

É em torno da empresa, ademais, que gravitam vários agentes econômicos nãoassalariados, como os investidores de capital, os fornecedores, os prestadores de serviços. 
Partindo deste panorama acerca da relevância e do papel da empresa, insta trazer à baila a figura do lucro como um verdadeiro fomento, capaz de garantir a manutenção e o constante crescimento das práticas empresariais.

É certo que esse lucro, apesar de devido, válido e justo, não pode ser a única finalidade da empresa, sob pena de contrariedade da regra constitucional que atribui à atividade empresarial o papel de garantidor da dignidade e da justiça social.

Por esta razão (MARÇAL, 1998, p. 117):

Todos direitos de natureza econômica e relacionados com a atividade empresarial têm pertinência com esse postulado (dignidade humana) e não podem ser a ele contrapostos. As faculdades de desenvolver atividades econômicas e de buscar o lucro são instrumentos de realização da dignidade de todas as pessoas humanas envolvidas, sejam os empresários, sejam os demais integrantes da comunidade (direta ou indiretamente relacionados com a empresa).

Nesta seara, a realização do lucro apenas é válida "em face do Direito se não for incompatível com a concretização de valores essenciais” (MARÇAL, 1998, p. 130).

Em outras palavras, a materialização do lucro somente alcança patamares aceitáveis, e de natureza lídima, quando conduzido ao coletivo, ou seja, quando transcendida a esfera privada e observados os interesses de uma maioria.

Sendo assim, ao destacar a justiça social como intento da ordem econômica a Constituição Federal acabou por condicionar a atividade empresarial à defesa de valores que ultrapassam os da esfera particular do empresário.

Todavia, em que pese a importância dos fins sociais atribuídos à empresa, estes devem ser observados sem se perder de vista medidas de natureza puramente empresariais, como é o caso lucro, pois segundo Amador Paes de Almeida (2010, p. 35):

Com efeito, vários interesses convergem para a empresa, ressaltando sua importância econômico-social. Entre outros sobressaem: o lucro do seu respectivo titular (o empresário individual ou coletivo - a sociedade empresária), lucro esse inegavelmente condicionado ao interesse social [...]

É ululante que para o alcance dos objetivos relacionados no artigo 170 da Constituição Federal (assim como aqueles elencados no artigo $3^{\circ}$ do mesmo codex), entre os 
quais se destaca a valorização do trabalho humano, a construção de uma sociedade justa, a existência digna, e o combate às diferenças regionais, o papel da empresa é vital.

No entanto, conforme lança Richard Ebeling (2016):

[...] quanto mais os criativos e industriosos prosperam neste arranjo produtivo e pacífico, mais eles são condenados e acusados de cometer algum tipo de "crime contra a humanidade" por causa dos lucros que auferem ao melhorar as circunstâncias das pessoas ao seu redor.

E neste contexto de diuturno enfrentamento entre a necessidade da atividade empresarial auferir lucros e a efetivação do invólucro social que lhe foi imposto pela norma constitucional, torna-se imperioso ter em mente que (REED, 2015):

[...] lucros representam muito mais do que a saúde financeira de uma empresa: eles indicam que a empresa está utilizando recursos escassos de maneira sensata e está satisfazendo os desejos dos consumidores; indicam que a empresa está genuinamente criando valor para a sociedade e está aprimorando a qualidade de vida e o progresso. Lucro é aquilo que todos nós buscamos quando, ao tentar melhorar nosso bem-estar, acabamos por melhorar o bem-estar de terceiros por meio de transações comerciais pacíficas e voluntárias.

Assim, "o lucro interessa à medida que constitui estímulo para que se aceite o risco da empresa" (SZTAJN, 2010, p. 131).

Esta, aliás, é a visão mais acertada acerca do tema, uma vez que, conforme defendem Moema Augusta Soares de Castro e Fabio Marques Ferreira (2011, p. 288):

O lucro é, portanto, a recompensa para aqueles que aceitam correr os riscos inerentes à atividade empresarial, que não são poucos. Não havendo lucro, o empresário não terá remuneração e, ainda assim, deverá arcar com os compromissos assumidos (salários, juros, contratos de fornecimento, despesas diversas, como a locação, água, luz, etc.)

$\mathrm{Na}$ verdade, não se pode olvidar que a busca pelo lucro no desempenho das atividades empresariais é de suma importância para o empresário, por ser, justamente, a materialização da devida recompensa por todo investimento realizado em uma prática que também é do interesse coletivo (ZANOTI, 2006, p. 25). 
Noutra ponta, pelo fato da empresa ter de seguir um norte legal de atuação, previsto no capítulo da Constituição Federal que trata da ordem econômica, embora ela possa (e deva) perseguir o lucro, tem que igualmente atender à uma finalidade social (ZANOTI, 2006, p. 77).

Isso implica em afirmar que a atividade empresarial possui sim a liberdade de iniciativa e a licença de ter como um dos seus fins o lucro. Entretanto, tal realidade não poderá se distanciar dos interesses e objetivos entabulados pela Constituição Federal no que tange à pretendida justiça social.

Nesta toada cumpre ressaltar que (ZANOTI, 2006, p. 89):

Há, portanto, um compromisso social do empresário para com a sociedade, pois se de um lado tem o direito a contabilizar lucros em decorrência de sua atividade empresarial, de outro deve pugnar para que seja assegurada uma existência digna, dentro de um quadro de justiça social, ao homem que está inserido no contexto em que ele se ativa.

Daí porque, ao considerar o lucro como mola mestra da atividade empresarial, e não como algo nefasto, ilegal ou espúrio, a empresa conquista uma postura muito mais efetiva, já que desta forma o empresário "promove seu enriquecimento pessoal e, em nível agregado, o desenvolvimento econômico do país" (BARBOSA, 2014, p. 273).

Logo, o entendimento que deve preponderar é aquele no sentido de que (CASTRO, 2006, p. 107):

[...] o lucro não é proibido, podendo até ser o objetivo principal da atividade, o que, no entanto, não afasta a obrigatoriedade de sua distribuição ser compatibilizada com a satisfação dos acionistas e investidores e o imperativo de solidariedade constante na Constituição Federal, propiciando, assim, benefícios concomitantes aos trabalhadores e à comunidade em geral.

E nesta esteira (SANTOS; ALVES JUNIOR; SOUZA-LIMA, 2016, p. 112):

Quanto maior o lucro da empresa melhor para os seus administradores, pois poderão continuar o processo de expansão, comprando mais maquinário, contratando mais pessoas, investindo na própria empresa, com o objetivo de sofisticar todo a dinâmica, satisfazendo os interesses internos e externos da empresa [...] 
Este é o elemento central do interesse de particulares em realizarem investimentos nas empresas: a assunção de lucros. E é por este motivo que "a satisfação do dever social do administrador deve ser conciliada com a busca do lucro lícito, sob pena de condená-las ao desaparecimento" (CASTRO, 2006, p. 114).

Portanto, os "lucros não apenas são uma condição necessária para o sucesso e a continuidade de um empreendimento, como também são moralmente justos, pois garantem a renda e o emprego de várias pessoas" (SIRICO, 2014).

Cabe ressaltar que é na empresa onde "congregam-se diversos interesses - o lucro do empresário, os salários, fundamentais à sobrevivência dos trabalhadores, os tributos, instrumentos indispensáveis à consecução dos fins objetivos do Estado" (ALMEIDA, 2010, p. $160)$.

Por isso é preciso evoluir para um entendimento mais abrangente acerca da necessária e inevitável convivência entre lucratividade e finalidade social da empresa, pois (WALD; FONSECA, 2005, p. 8):

\begin{abstract}
A visão realista do mundo contemporâneo considera que não há mais como distinguir o econômico do social, pois ambos os interesses se encontram, se interpenetram e se compatibilizam na empresa, núcleo central da produção e da criação da riqueza, que deve beneficiar tanto o empresário como os empregados e a própria sociedade $[\ldots]$
\end{abstract}

Assim, a compreensão ideal acerca da empresa é aquele no qual prevalece o convívio harmonioso, e com a devida carga de proporcionalidade, entre os interesses particulares e aqueles direcionados ao bem-estar da coletividade, uma vez que (BAUMAN, 1998, p. 10):

[...] não há nenhum ganho sem perda, e a esperança de uma purificação admirável dos ganhos a partir das perdas é tão fútil quanto o sonho proverbial de um almoço de graça - mas os ganhos e perdas próprios a qualquer disposição de coabitação humana precisam ser cuidadosamente levados em conta, de modo que o ótimo equilíbrio entre os dois possa ser procurado.

Desta feita, nem o lucro precisa ser o maior pesadelo da classe empresarial (ou o monstro mais abominado pelo senso comum), nem os fins sociais devem ser fatores impeditivos do proveito econômico pretendido pelo empresário.

\footnotetext{
- Lucros estes aqui considerados quando obtidos de maneira justa e sem qualquer nota de abusividade.
} 
Ambos, fim social e lucro, devem coexistir no âmbito da atividade empresarial numa autêntica simbiose em prol do crescimento econômico do país.

\section{CONCLUSÃO}

O presente trabalho buscou tratar da empresa como principal elemento de efetivação da ordem econômica constitucional e, com isso, dos valores sociais inseridos na Constituição Federal.

Neste compasso, a empresa deixou de ser uma atividade de simples circulação de bens ou serviços e sua finalidade tornou-se muito mais ampla do que a simples busca pelo lucro.

$\mathrm{Na}$ verdade, a empresa passou a ser um agente social, responsável por realizar valores como a existência digna, o pleno emprego, a redução de desigualdades, entre outros.

Em outras palavras, deixou a empresa de ser um instrumento de concretização dos propósitos individualistas do empresário e passou a ser uma ferramenta dos princípios constitucionais estabelecidos pela ordem econômica nacional.

E é justamente neste contexto que surge o maior desafio da empresa: conciliar os interesses essenciais da livre iniciativa, entre eles o lucro, e, ao mesmo tempo, garantir meios de concretização da justiça social.

Daí o objetivo do presente artigo, qual seja, o de promover o debate sobre esta relação tormentosa, porém crucial, entre a essência lucrativa da empresa e seu papel social.

Com isso em mente, buscou-se demonstrar que os deveres sociais a serem realizados pelos empresários não podem ser vistos como entraves à persecução do lucro. Ou seja, lucro e fim social não são incompatíveis.

Da mesma forma, procurou-se evidenciar que é através do lucro que os valores entabulados pela Constituição Federal podem ser efetivados no âmbito da atividade empresarial.

Daí a relevância de se tratar do tema de maneira que o lucro deixe de ser rejeitado por parte da sociedade, bem como não seja mais visto como algo nefasto. Pelo contrário, é necessário aceitar o lucro como a principal recompensa dos empresários, de maneira a, inclusive, servir de estímulo para o aumento da produtividade e, com isso, criar mais condições da empresa realizar os ditames sociais encartados na Constituição Federal. 
Somente com a aceitação do lucro como um dos elementos essenciais da empresa será possível gerar mais benefícios coletivos e atingir a tão almejada redução das desigualdades sociais.

Disso resulta a pretensão do trabalho em voga, ou seja, a de ampliar a discussão sobre o lucro e seu papel de catalisador da atividade empresarial, de forma, inclusive, a consolidá-lo como instrumento de realização dos fins sociais da empresa.

\section{REFERÊNCIAS}

ADMINISTRADORES - PORTAL DA ADMINISTRAÇÃO. O Estigma do Lucro. Disponível em: <http://www.administradores.com.br/noticias/negocios/o-estigma-dolucro/4402/>. Acesso em: 13 jan. 2017.

ALMEIDA, Amador Paes de. Direito de Empresa no Código Civil. $3^{\text {a }}$ ed. rev. e atual. São Paulo: Saraiva, 2010.

ARAUJO, Gisele Ferreira de. Responsabilidade social empresarial (res) e o desenvolvimento sustentável no contexto do moderno direito regulatório - iminência de um instituto jurídico? In: SOUZA, Carlos Aurélio Mota de (Coord.). Responsabilidade Social das Empresas. São Paulo: Editora Juarez de Oliveira, 2007. p. 111 - 130.

BARBOSA, Leonardo Garcia. Conceito e função econômica de empresa. Revista e Informação Legislativa, Brasília, ano 51, n. 202, p. 251-277, abr./jun. 2014. Disponível em: <http://www2.senado.leg.br/bdsf/handle/id/503047>. Acesso em: 12 jan. 2017

BAUMAN, Zygmunt. O Mal-Estar da Pós-Modernidade. Tradução Mauro Gama e Cláudia Martinelli Gama. Rio de Janeiro: Zahar, 1998.

BRASIL. Superior Tribunal de Justiça. Processual civil. Tributário. Mandado de segurança. Recurso administrativo. Decadência. Termo inicial. Iss. Contribuinte do imposto. Empresa. Exercício de atividade econômica. Finalidade lucrativa. Enquadramento não-caracterizado. Recurso Especial Cível $\mathbf{n}^{\mathbf{0}}$ 623367. Recorrente: Município do Rio de Janeiro. Recorrido: Escritório Central de Arrecadação e Distribuição - ECAD. Relator: Ministro João Otávio de Noronha. Brasília, 09 de agosto de 2004. Disponível em: $<$ http://www.stj.jus.br/SCON/jurisprudencia/doc.jsp?livre=empresa+finalidade+lucrativa\&b= ACOR\&p=true\&t=JURIDICO\&l=10\&i=28>. Acesso em: 11 jan. 2017.

BULGARELLI, Waldirio. Direito Comercial. 13ª ed. São Paulo: Atlas, 1998.

CASTRO, Carlos Alberto Farracha de. A Preservação da Empresa no Novo Código Civil. 174 f. Tese (Doutorado em Direito) - Setor de Ciências Jurídicas, Universidade Federal do Paraná, Curitiba, 2006. Disponível em: <http://acervodigital.ufpr.br/handle/1884/4802>. Acesso em: 10 jan. 2017. 
CASTRO, Moema Augusta Soares de; FERREIRA, Fabio Marques. A atuação da empresa e sua organização no mercado. Revista da Faculdade de Direito da Universidade Federal de Minas Gerais, Belo Horizonte, n. 59, p. 277-306, jul./dez. 2011.

CAVALli, Cassio Machado. Empresa, Direito e Economia: elaboração de um conceito jurídico de empresa no direito comercial brasileiro contemporâneo a partir do dado teórico econômico. 304 f. Tese (Doutorado em Direito), Universidade Federal do Rio Grande do Sul, Porto Alegre, 2012. Disponível em: <http://www.lume.ufrgs.br/handle/10183/55327>. Acesso em: 10 jan. 2017.

CHOMSKY, Noam. O Lucro e as Pessoas. Tradução Pedro Jorgensen Jr. Rio de Janeiro: Bertrand Brasil, 2002.

COELHO, Fábio Ulhoa. Manual de Direito Comercial. $16^{\mathrm{a}}$ ed. rev. e atual. São Paulo: Saraiva, 2005.

COMPARATO, Fábio Konder. Direito Empresarial: estudos e pareceres. São Paulo: Saraiva, 1995.

EBELING, Richard. Quanto mais a livre iniciativa retira pessoas da pobreza, mais ela é desprezada. Mises Brasil, São Paulo, 28 out. 2016. Disponível em: <http://www.mises.org.br/Article.aspx?id=2549>. Acesso em: 13 jan. 2016.

FAVATA, Angelo. Dizionario dei Termini Giuridici: una racolta di vocaboli, instituti, termini, espressioni e definizioni giuridiche. 26 ${ }^{\mathrm{a}}$ ed. Piacenza: Casa Editrice la Tribuna, 2007.

FERNANDEZ, João Alberto da Costa Ganzo. A caracterização da atividade empresária: identificação dos elementos de empresa sob a ótica sistêmica. Revista da Esmesc, Florianópolis, v. 17, n. 23, p. 259-283, 2010. Disponível em: <https://revista.esmesc.org.br/re/article/view/11/22>. Acesso em: 10 jan. 2017.

FERRI, Giuseppe. Manuale di Diritto Commerciale. 12 ${ }^{\mathrm{a}}$ ed. Torino: Utet Giuridica, 2006.

GONÇALVES, Wilson José. Função social da empresa e responsabilidade socioambiental: sustentabilidade e desenvolvimento. In: GONÇALVES, Wilson José (Coord.). Atualidade Empresarial. Campo Grande: UFMS, 2007. p. 11-23.

GRAU, Eros Roberto. A Ordem Econômica na Constituição Federal de 1988. $16^{\mathrm{a}}$ ed. rev. e atual. São Paulo: Malheiros, 2014.

HUBERMAN, Leo. História da Riqueza do Homem. 17ª ed. Rio de Janeiro: Zahar, 1981.

JUSTEN FILHO, Marçal. Empresa, ordem econômica e constituição. Revista de Direito Administrativo, Rio de Janeiro, v. 212, p. 109-133, abr./jun. 1998. Disponível em: <http://bibliotecadigital.fgv.br/ojs/index.php/rda/article/view/47171/45639>. Acesso em: 12 jan. 2017. 
MAMEDE, Gladston. Manual de Direito Empresarial. 4ª ed. São Paulo: Atlas, 2009.

MIRANDA, Maria Bernadete. A empresa, o empresário e o empreendedor no contexto do moderno direito empresarial. Revista Virtual Direito Brasil, Santana de Parnaíba, v. 3, n. 1, p. $1-15,2009.2017$. Disponível <http://www.direitobrasil.adv.br/index_arquivos/Page1060.htm>. Acesso em: 11 jan. 2017.

REED, Lawrence W. Para realmente gerarem valor para a população, empresas têm de ter lucro. Mises Brasil, São Paulo, 11 nov. 2015. Disponível em: <http://www.mises.org.br/Article.aspx?id=2113>. Acesso em: 13 jan. 2016.

REQUIÃO, Rubens. Curso de Direito Comercial. v. 1. $29^{\mathrm{a}}$ ed. rev. e atual. São Paulo: Saraiva, 2010.

SANTOS, Rodrigo Gehr Dobbins do; ALVES JUNIOR, Sérgio Itamar; SOUZA-LIMA, José Edmilson de. A (i)responsabilidade social-econômica da empresa liberal do século XXI. In: REIS, Clayton; OLIVEIRA, Francisco Cardozo; RODRIGUES, Maria Lucia de Barros (Coord.). Diálogos (im)pertinentes: negócio, empresa e afetação da cidadania. Curitiba: Instituto Memória, 2016. p. 103-118.

SIMULA, Pertti. A Perversidade do Sistema Capitalista. O que fazer? Disponível em: <http://www.mst.org.br/2016/02/15/o-nosso-sistema-de-poder-e-perverso-o-que-fazer.html>. Acesso em: 12 jan. 2017.

SIRICO, Robert. A função social e moral dos lucros. Mises Brasil, São Paulo, 15 jan. 2014. Disponível em: <http://www.mises.org.br/Article.aspx?id=1780>. Acesso em: 13 jan. 2017.

SOUZA, Carlos Aurélio Mota de. São Paulo empresarial: responsabilidade econômico-social. In: SOUZA, Carlos Aurélio Mota de (Coord.). Responsabilidade Social das Empresas. São Paulo: Editora Juarez de Oliveira, 2007. p. 39-56.

SZTAJN, Raquel. Teoria Jurídica da Empresa: atividade empresária e mercados. $2^{\text {a }}$ ed. São Paulo: Atlas, 2010.

WALD, Arnold. A empresa no terceiro milênio. In: WALD, Arnold; FONSECA, Rodrigo Garcia da (Coord.). A Empresa no Terceiro Milênio: aspectos jurídicos. São Paulo: Editora Juarez de Oliveira, 2005. p. 3-38.

ZANOTI, Luiz Antônio Ramalho. A Função Social da Empresa Como Forma de Valorização da Dignidade da Pessoa Humana. 240 f. Dissertação (Mestrado em Direito), Universidade de Marília, Marília, 2006. Disponível em: <http://www.unimar.br/pos/trabalhos/trabalhos.php?area=3\#>. Acesso em: 10 jan. 2017.

ZANZANELLI, Nelson Freitas. A necessidade de socialização da atividade empresarial. Revista da Faculdade de Direito da Universidade São Judas Tadeu, São Paulo, n. 2, p. 146-161, 2014. Disponível em: <http://www.usjt.br/revistadireito/sumario-2.html>. Acesso em: 12 jan. 2017. 